\title{
Assessment of the potential impacts of climate change on the hydrology at catchment scale: modelling approach including prediction of future drought events using drought indices
}

\author{
M. Afzal ${ }^{1,2} \cdot$ R. Ragab ${ }^{1}$ (D)
}

Received: 25 September 2019 / Accepted: 24 August 2020 / Published online: 10 September 2020

(c) The Author(s) 2020

\begin{abstract}
In this study, the Distributed Catchment-Scale Model, DiCaSM, was used to study the impact of climate change on the hydrology of the Eden catchment, north east of Scotland. As a first step, the model was successfully calibrated and validated for a 42 years period. The DiCaSM model was then used to study the impact of climate change on the water availability. Data from the UKCP09 Climate change scenarios for the 2010-2039, 2040-2069 and 2070-2099 periods, considering three gas emission scenarios (low, medium and high), were applied. The results indicated that the greatest decrease in streamflow and groundwater recharge was projected to happen under the high emission scenarios towards the end of the century, i.e. between 2070 and 2099. This would mainly be due to the summers becoming drier. Meanwhile, the projected increase in winter precipitation did not contribute much towards groundwater recharge due the projected increases in evapotranspiration and soil moisture deficit.

The following drought indices were calculated and were found to be effective in predicting different types of droughts: the Standardized Precipitation Index, SPI, and the Standardized Precipitation Evaporation Index, SPEI, the Reconnaissance Drought Index, RDI, the modified adjusted RDI, the Soil Moisture Deficit, SMD and the Wetness Index, WI. The findings of the study have broader implications in water resources management considering the future changes in climate.
\end{abstract}

Keywords Climate change $\cdot$ DiCaSM model $\cdot$ Drought indices $\cdot$ Eden catchment $\cdot$ hydrological modelling

\section{Introduction}

Scotland is perceived to be a country with an abundance of precipitation and ample water resources. Water resources, however, are affected by climate variability and land use practices and certain areas of Scotland have experienced droughts in the recent past. Water demand and supply varies greatly across the UK. The North of the UK, and Scotland in particular, is less populated than the rest of the UK and receives significant precipitation but it is not necessarily true that a region which is generally considered as waterrich, will always meet its water requirements over the entire

R. Ragab

rag@ceh.ac.uk

1 UK Centre for Ecology \& Hydrology (UK CEH), Wallingford OX10 8BB, Oxfordshire, UK

2 School of Natural Sciences, The University of Central Lancashire, Preston, UK region. Studies demonstrated that the precipitation gradient across the UK has been accentuated with the northwest becoming wetter, notably in the winter, and the southeast becoming drier during the summer (Mayes, 2000).

Alexander et al. (2005) reported that precipitation over the UK had been on the increase since the 1950s, with precipitation coming in frequent short periods of high intensity rainfall. Perry and Devon (2006) reported that, since the 1970s, there had been a continuous increase in the amount of rain received in Scotland (Werritty and Sugden, 2012) confirmed this trend. In 2006, the average precipitation in Scotland was found to be in excess of $1400 \mathrm{~mm}$ per year, making the country the third wettest in Europe, after Switzerland and Norway (Barnett et al., 2006). While this would suggest there should be no issue with water supply in Scotland, Hulme (2002) noticed the rain was unevenly distributed, with the east of the country only receiving half of the precipitation received in the west. This implies that, especially during the summer months, water supply in eastern Scotland might be at risk. There have been water 
shortages, such as those of the early 1970s when different parts of Scotland experienced severe drought especially in East Scotland (Smith, 1977). This was due to low rainfall for several months, higher water losses due to evapotranspiration, a limited amount of recharge to aquifers and lower runoff of water to rivers. Evapotranspiration is another key component of the hydrological cycle influencing catchment water availability. With a warming atmosphere, an increase in evaporation is expected (Fisher and Rubio, 1997). Using the UK Met Office Rainfall and Evaporation Calculation System (MORECS), Kay et al. (2013) reported an increase in evapotranspiration during the period 1961-2012 across the UK, including in Scotland, but with spatial and seasonal variations. Nonetheless, climate models project an increase in evaporation in the summer due to climate change (Wade et al., 2013). This increase in evaporation, combined with greater variations in rainfall between seasons and years will inevitably influence catchment runoff and consequently the water resources.

The two main resources of water in the UK are surface water and the groundwater. In England and Wales groundwater accounts for over $35 \%$ of the total water supply, while in Scotland approximately $93 \%$ of water supply is extracted from surface sources (MacDonald et al., 2005). The relatively low groundwater use in Scotland is due to its limited availability for geological reasons, with highly productive aquifers restricted to the Southwest and Fife region (studied catchment area) where they contribute significantly to the water supply. In the drier areas of eastern Scotland, use of water for irrigating crops is common, creating further strains on water resources with rivers occasionally drying up (Adeloye and Low, 1996). The studied Eden catchment is in the relatively dry eastern region of Scotland. The River Eden is a significant source of the water supply, particularly for agriculture. This study applied the DiCaSM model (Ragab et al., 2010; Ragab and Bromley, 2010), which has been successfully applied under different climatic conditions, e.g. in the UK (Ragab and Bromley, 2010; Afzal and Ragab 2019), in Cyprus (Ragab et al., 2010), in the semi-arid region of the northeast of Brazil (Montenegro and Ragab, 2012, 2010) and in the south of Italy (D'agostino et al., 2010), not only under climate change scenarios but also applying different possible land use changes. In Scotland, although a few studies applied UKCP09 data to assess the river flows (Thompson, 2012; Afzal et al., 2015b) and to assess future drought risk (Gosling, 2014), little focus has been given to application of different drought indices under current and future climate change scenarios, these could potentially be used to assess meteorological, hydrological and agricultural droughts to quantify the impact of climate change in Scotland. The studied catchment is important because of the land use practices in the area and water abstraction for agriculture, while river flows are low, especially during the summer season.
Therefore, the application of the multiple drought indices under current and future climate changes could potentially be used to identify the severity of droughts, including hydrological and agricultural droughts. The findings of the study could help in planning for perhaps extra water infrastructure work such as more reservoirs, expanding the storage capacity of the existing reservoirs, installing water transfer pipelines, planning for irrigation water demand under different climatic conditions and also be of importance for decision making by the water managers, policymakers and stakeholders, and be helpful in managing the climate change impact on water resources.

\section{Catchment location and characteristics; data and methodology}

\section{The catchment}

The Eden catchment is situated in Eastern Scotland, in the north of the Fife region, with the latitude of $56.3^{\circ} \mathrm{N}$ and longitude $2.9^{\circ} \mathrm{E}$. The catchment drains an area of $309 \mathrm{~km}^{2}$ and $307.4 \mathrm{~km}^{2}$ of the catchment lies upstream of the gauging station at Kemback (Fig. 1).

The catchment is predominantly low-lying [mean elevation 100 mAOD (meters above ordnance datum/above mean sea level) increasing to $\sim 500 \mathrm{mAOD}$ in the Lomond Hills on the southern boundary], is situated between the estuaries of 'Firth of Forth' to the South and the 'Firth of Tay' to the North and has a mixed geology (Morris et al., 1990; Morris and Flavin, 1994). The aquifers of the study catchment are productive, this is exceptional for Scotland where only $1 \%$ of aquifers are highly productive, $21.6 \%$ are moderately productive and the remaining $77.4 \%$ are nonproductive and inoperable (Fig. 2). Because of the high dependence of Scotland on surface water supplies, the availability of water resources is strongly influenced by rainfall variability.

\section{Historic data and catchment characteristics}

The mean annual precipitation of the catchment for the base line period (1961-1990) is $799 \mathrm{~mm}$ and the mean annual river flow is $4.05 \mathrm{~m}^{3} \mathrm{~s}^{-1}$. Over the historic period (1961-1990), the minimum flow, $0.57 \mathrm{~m}^{3} \mathrm{~s}^{-1}$, was recorded in August 1989 and the peak flow, $68.85 \mathrm{~m}^{3} \mathrm{~s}^{-1}$, occurred in February 1977, soon after the well-known 1976 drought. For the modelling study, the catchment was discretized into 369 regular $1 \mathrm{~km}$ grid squares (Fig. 3). The daily climate data required for the model were rainfall, temperature, wind speed, net radiation and actual vapour pressure. The daily distributed data were obtained from the Climate, Hydrology and Ecology research Support System (CHESS) (Tanguy 
Fig. 1 Eden catchment boundary, stream route, gauging station location, location of the catchment on the UK map with hydrogeology of the catchment. Source: Morris et al. (1990); Morris and Flavin (1994)

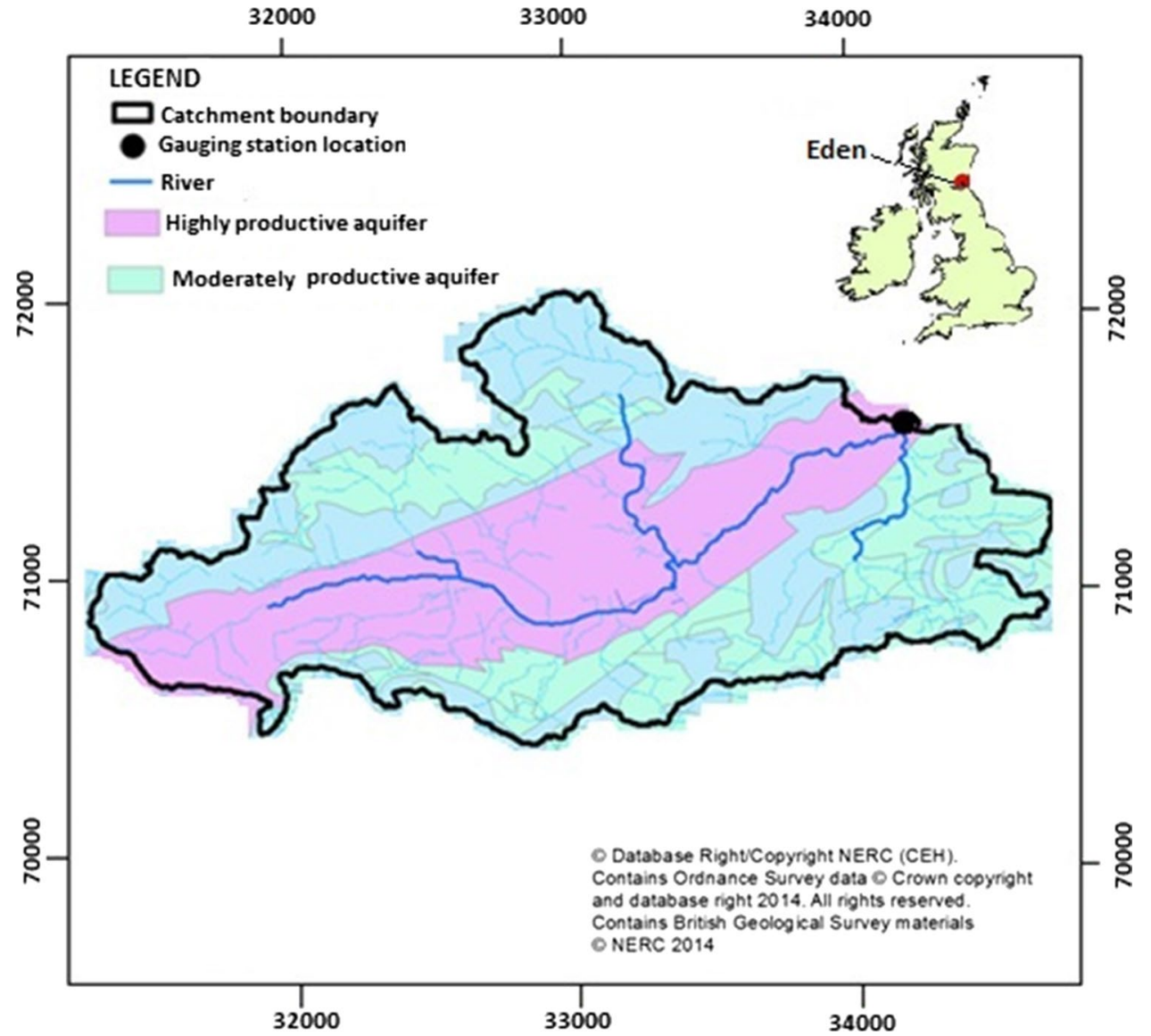

et al., 2016; Robinson et al., 2015). The historic continuous climatic variables data were available from 1961 onwards, whereas the gauged daily river-flow was available from 1969 until 2012 (NRFA, 2014). Analysis of the monthly mean river flow anomalies, using a six-month aggregation period, reveals significantly below average flows in the 1970s (Fig. 4).

Figure 5 shows that $75 \%$ of the Eden catchment is prime agricultural land (crops and grass area). Therefore, water resources management in the catchment is very important due to need to manage the good quality groundwater aquifers and the groundwater abstraction as well as the water abstraction from the River Eden and its tributaries, mainly for crop irrigation, but, as the river runs low in summer farmers are turning more to groundwater abstraction. Personal communication with Scottish Environmental Protection Agency (SEPA) reported a shift from grain cultivation to fruits and vegetable crops, as in the last decade, more water abstraction licenses have been issued under Controlled Activity Regulations (CAR) due to the fact that fruits and vegetables require irrigation, while barley and wheat are mainly rain-fed. Figure 6 , based on agriculture census data, shows a diverse variety of agriculture practices within the catchment with barley still being the main agriculture crop (Defra, 2015).

\section{The DiCaSM model}

The physically based DiCaSM model was applied on Eden catchment. DiCaSM is the acronym for the Distributed Catchment Scale Model (Ragab and Bromley, 2010; Ragab et al., 2010; Afzal and Ragab 2019). This model has been developed to estimate the catchment water balance and to account for the impact of the changes in climate and land use on the overall water balance. The DiCaSM model calculates rainfall interception by trees, by the grass and by crops. The infiltration rate, surface run off, groundwater recharge, potential and actual evapotranspiration of mixed vegetation, soil moisture, plant water uptake and stream flow.

The model has the option to scale the soil moisture as wetness index. The scaled values range from 0 to 1 for any given day. The value of " 1 " means the catchment is wet (at maximum soil moisture), while the value of " 0 " means the catchment is dry (at minimum soil moisture). The Wetness Index WI has the advantage of reducing the spatial variability between different locations. On a certain day, WI can be calculated as: 
Fig. 2 Characteristics of the Scottish aquifers

\section{Features of scottish aquifers}

Highly productive aquifer

Moderately productive aquifer

Low productivity aquifer
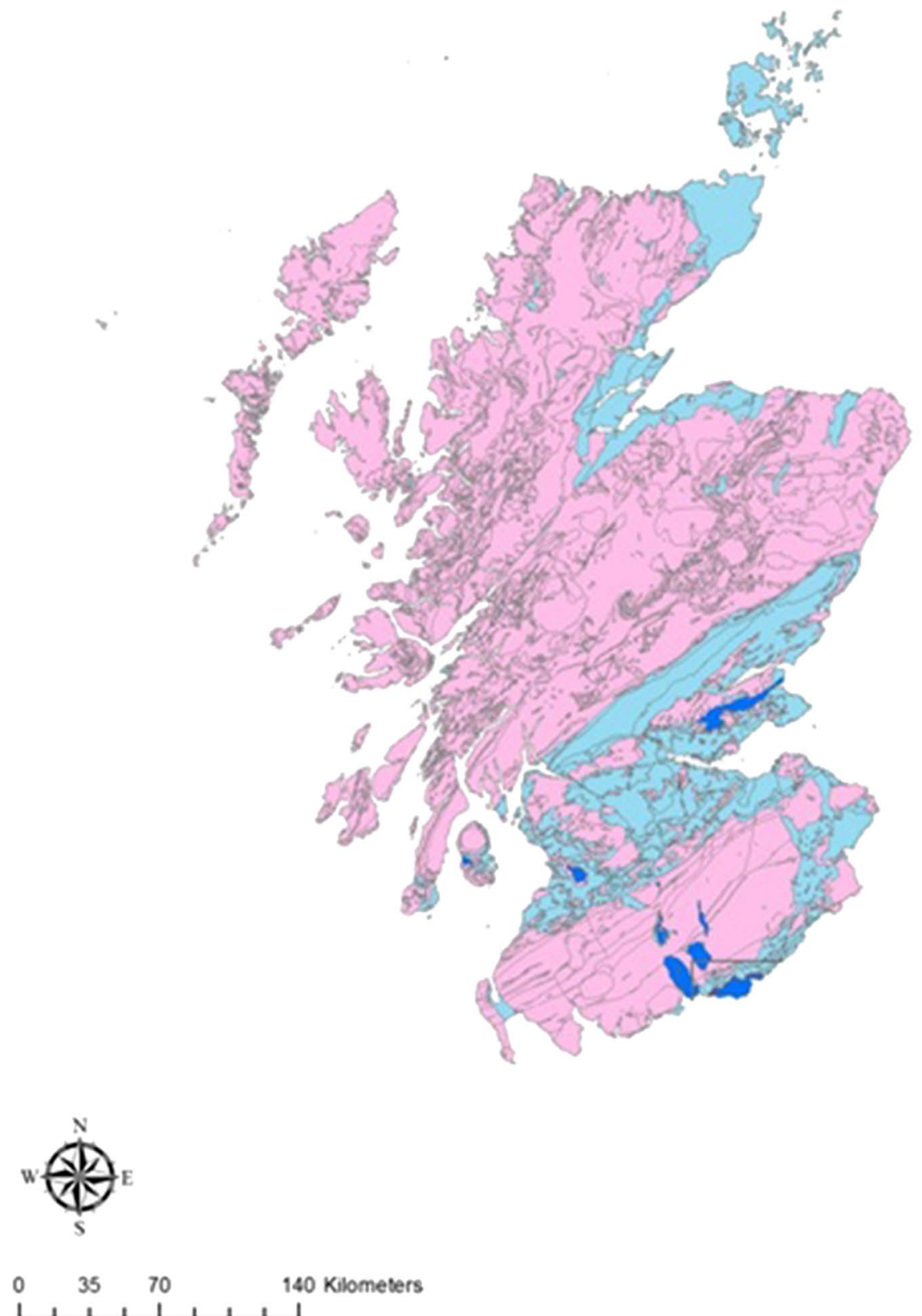


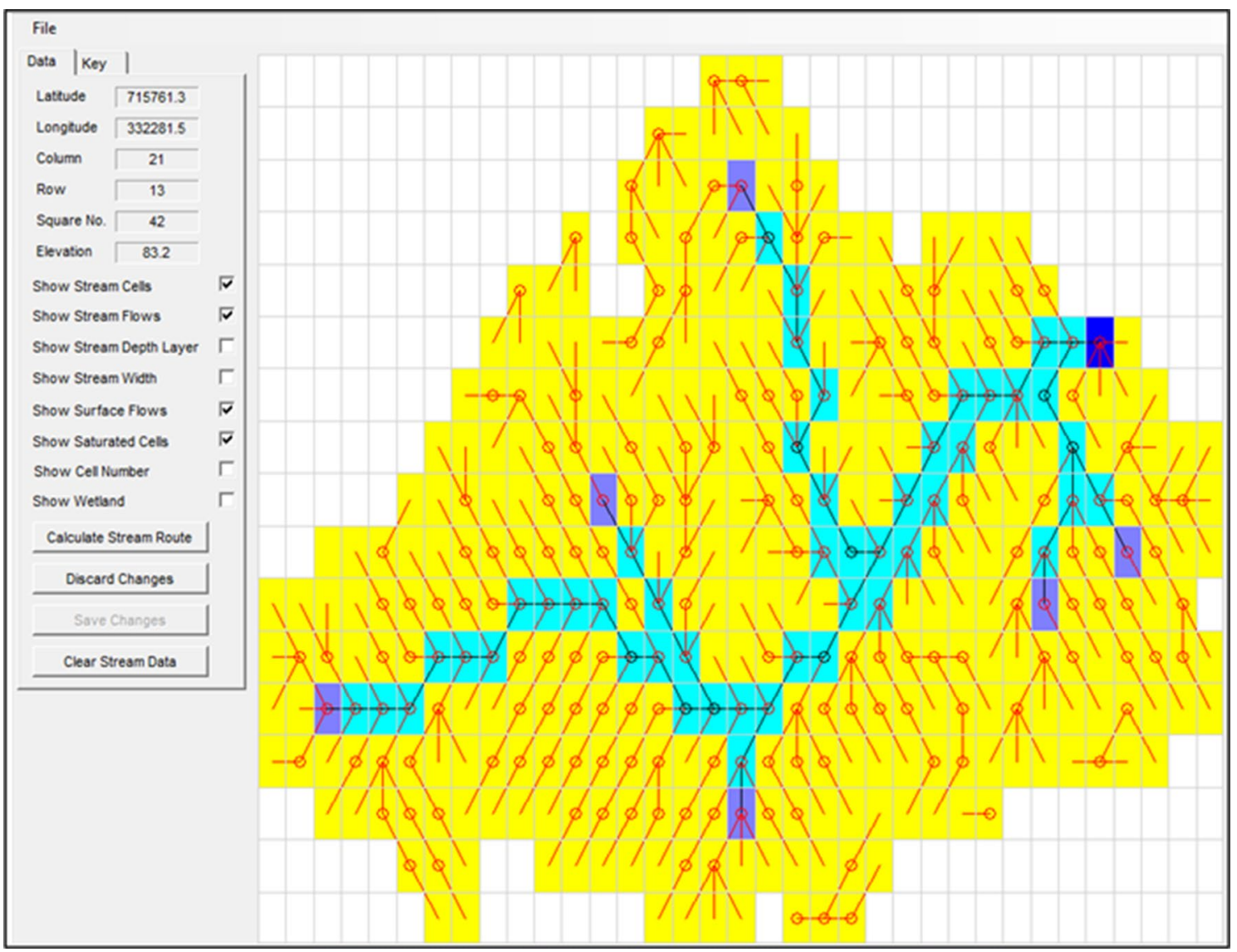

Fig. 3 Stream and surface flow map of Eden catchment generated by DiCASM model

$$
W I=\frac{\sum\left[\left(S M_{z}\right)-\left(S M_{z}\right) \min \right]}{\sum\left[\left(\left(S M_{z}\right) \max -\left(S M_{z}\right) \min \right]\right.}
$$

$S M z$ is the soil moisture at depth $z, S M z \max$, and $S M z$ min are the maximum and minimum observed soil moisture at depth $\mathrm{z}$ over the simulated/measurement period, respectively. Further details about the equations used in the model are given in Ragab and Bromley (2010). The model calibration is commonly carried out over a short period while the validation period varies from a few years to the entire available record.

\section{Calibrating model parameters}

For the model calibration, optimization algorithm to identify the best set of parameters has been used. There are six key model parameters that significantly affect the streamflow. These parameters are the percentage of flow routed to stream, catchment storage/time lag coefficient, base flow coefficient, exponent function to describe the peak flow, stream storage/time lag coefficient and stream bed infiltration/leakage. The calibration process involves running an optimization procedure which is based on a simple iteration algorithm in which each of the six optimization parameters were assigned maximum and minimum values. The whole iteration process was carried out using the number of steps between maximum and minimum values of each parameter. The model calculates the Nash-Sutcliffe efficiency value, $N S E$, the In NSE, the coefficient of determination, $R^{2}$, the total water volume simulated, and total volume observed for the simulated period. The benefit of running the iteration process is to find the best combined values of the six parameters that provide the maximum NSE value. The streamflow of the year 2012 was selected for calibration. Other periods were used for validation.

\section{Evaluating model efficiency}

Several statistical indices were used as model performance indicators to evaluate the goodness of fit and compare the simulated and observed streamflow data. This study applied the Nash-Sutcliffe Efficiency (NSE) coefficient (Nash and Sutcliffe, 1970), as this is the most widely used coefficient to assess the performance of hydrological models (Singh et al., 2010). The NSE 


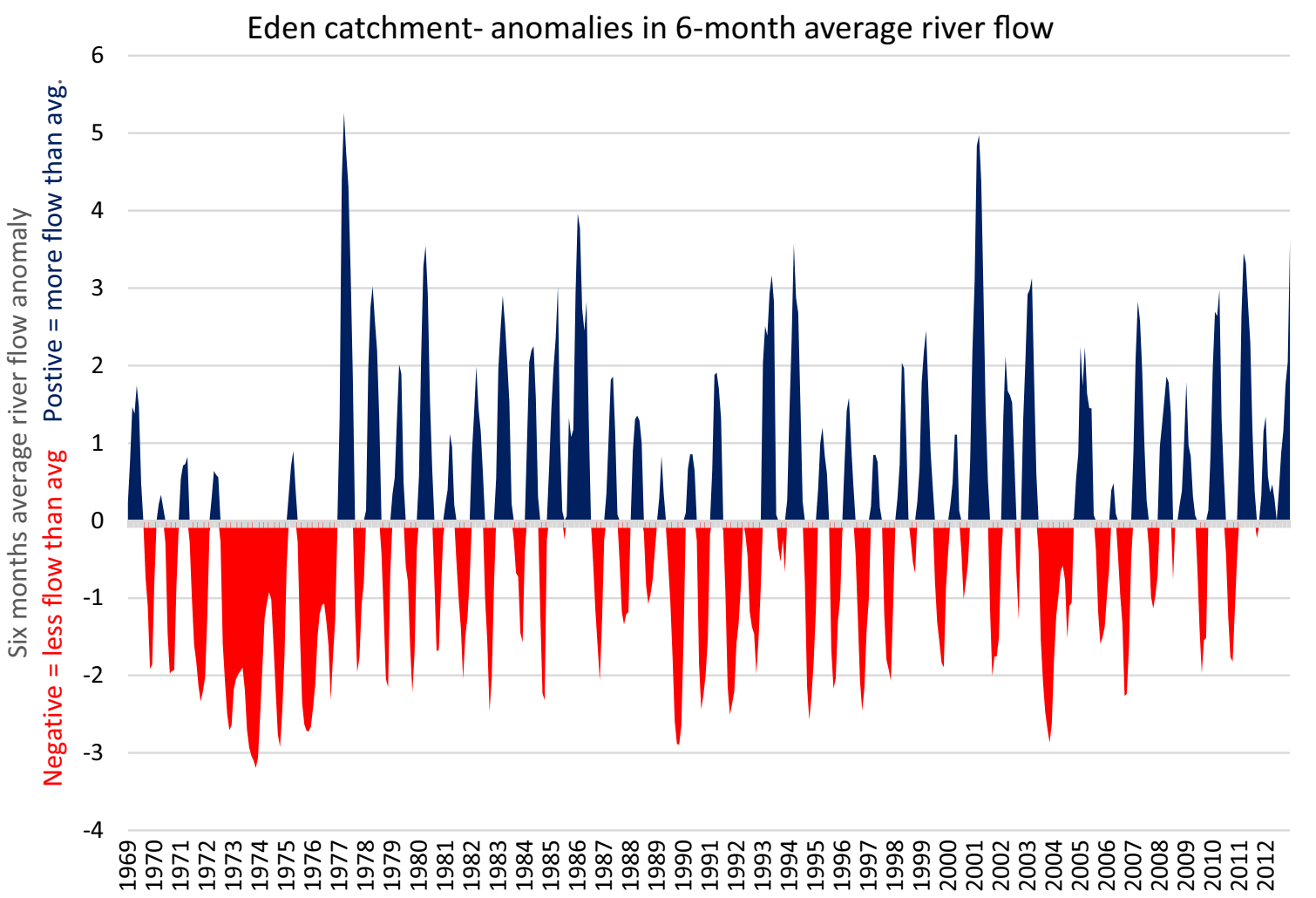

Fig. 4 Anomalies in six-month average river flow for Eden at Kemback for the 1969-2012 period

coefficient is calculated by Eq. 2. A NSE of $100 \%$ would indicate a perfect match of simulated and observed data.

$N S E=100 \%-\frac{\sum_{i=1}^{n}\left(O_{i}-S_{i}\right)^{2}}{\sum_{\mathrm{i}=1}^{\mathrm{n}}\left(O_{i}-\right)^{2}}$

where $O_{i}$ and $S_{i}$ refer to the observed and simulated river flow data, respectively, and $\bar{O}$ is the mean of the observed data. The calibration procedure for streamflow consisted of adjusting the six tunable parameters to achieve the best model fit according to the NSE, and the coefficient of determination, $\mathrm{R}^{2}$ (Eq. 3):

$R^{2}=\left\{\frac{1}{N} \frac{\sum\left[\left(y_{0}-\overline{y_{0}}\right] \overline{\left(\overline{y_{s}-\overline{y_{0}}}\right.}\right.}{\sigma y_{0}-\sigma y_{s}}\right\}$

where $\mathrm{y}_{\mathrm{s}}$ is the simulated value, $\mathrm{y}_{\mathrm{o}}$ is the measured value, $N$ is the total number of observations, $\bar{y}_{\mathrm{o}}$ is the average measured value, $\bar{y}_{\mathrm{s}}$ is the average simulated value, $\sigma y_{0}$ is the observed data standard deviation and $\sigma y_{s}$ is the simulated data standard deviation. The values of this index can range from 0 to 1 , with one indicating perfect fit.

\section{Application of future climate change scenarios of UKCP09}

To study the impact of future climatic change on water supply, this study applied the UK Climate Projection Scenarios (UKCP09). Detailed information about the UKCP09 is provided in Murphy et al. (2007) and Murphy et al. (2009). The UKCP09 provides projections for the changes in the amount and seasonal variation of precipitation, temperature and other climatic variables, such as relative humidity and sunshine hours. In this study net radiation was calculated using the sunshine hours data from the climate model according to Allen et al. (1998). The UKCP09 climate change projections are provided for three greenhouse gas emission scenarios relative to the 1961-1990 baseline time period. The UKCP09 provide monthly, seasonal and annual, probabilistic change factors at $25 \mathrm{~km}$ grid square resolution for the key climatic variables, including precipitation and temperature. UKCP09 also provides daily weather generator output data at a $5 \mathrm{~km}^{2}$ resolution for more climate variables, such as relative humidity and sunshine hours, in 


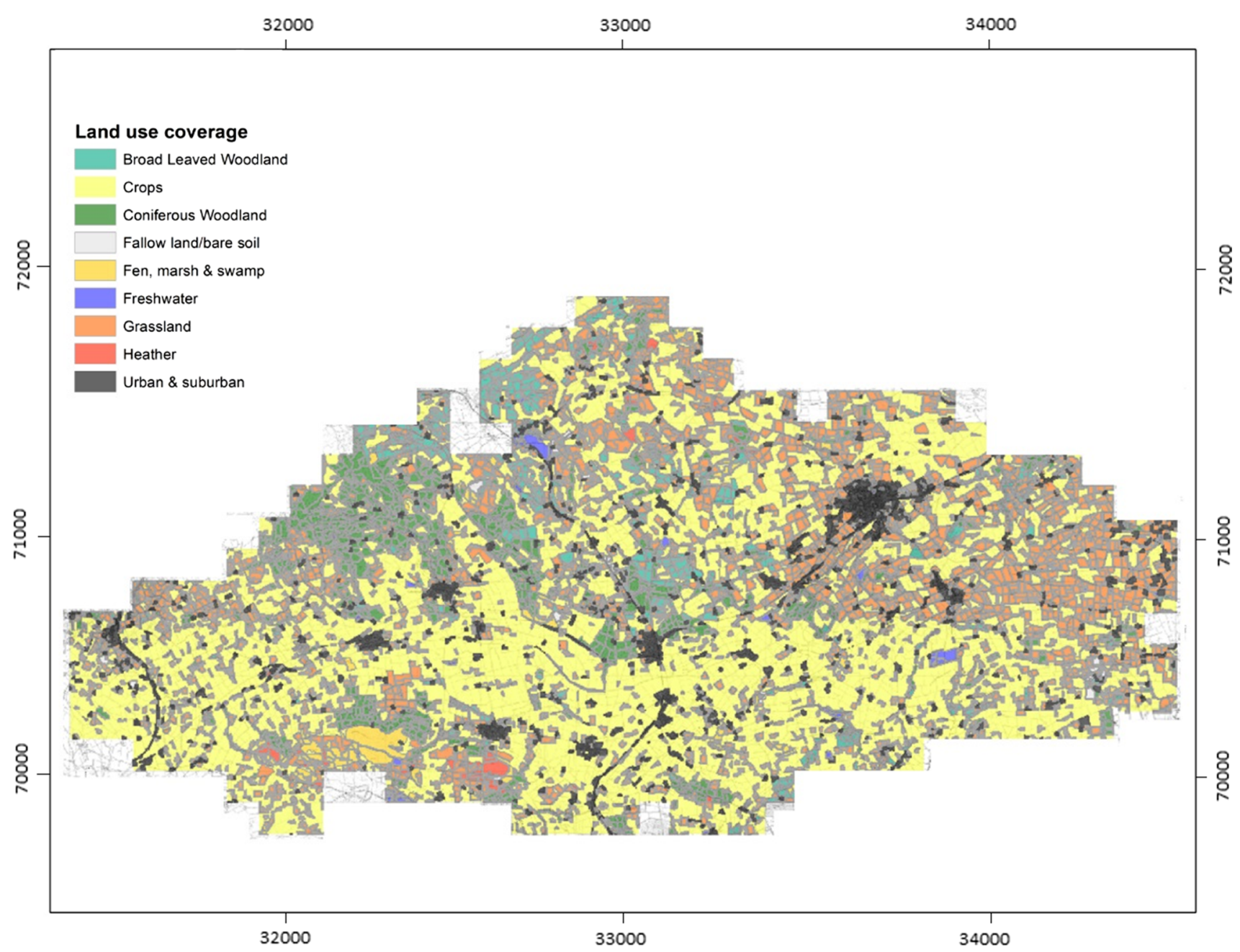

Fig. 5 Land use coverage of the Eden catchment Source: Defra, 2015

addition to rainfall and temperature. This study selected all three greenhouse gas emission scenarios (low, medium and high) for three 30-year periods: 2020's (2010-2039), 2050's (2040-2069) and 2080's (2070-2099). For the initial exploratory analysis, simplified change factors were derived from UKCP09 joint probability central estimates. The joint probability plot was used to generate seasonal climatic change factors (\% change in rainfall and change in temperature ${ }^{\circ} \mathrm{C}$ ) to apply as an input to the DiCaSM model. For the detailed weather generator simulations, 100 realizations of the daily time series data were generated in order to account for the uncertainty associated with the scenarios. Table 1 shows the changes in precipitation and temperature under different climate change scenarios for three selected time periods, the 2020s, 2050s, and 2080s based on the joint probability plots of UKCP09 compared to the 1961-1990 'baseline' period (average annual rainfall $799 \mathrm{~mm}$; average temperature $7.8^{\circ} \mathrm{C}$ for the baseline data).
The seasonal temperature shows an increase with emissions scenario and time, particularly in summer and autumn whereas the precipitation is showing rainfall decreases in summer and increases in winter. The seasonal climate change factors of temperature ( \pm change in $\left.{ }^{\circ} \mathrm{C}\right)$ and rainfall (\% change in rainfall) at the most likelihood (central estimate) probability level were input to the DiCaSM model and applied to the 1961-1990 baseline climate data. Although a complete impact analysis should consider sampling the full range of probabilistic climate projections, this simplified approach was selected to provide an initial exploratory analysis. Consideration of climate projection uncertainty was included by also using the weather generator data approach. Daily projected data of temperature, rainfall, relative humidity/vapour pressure and radiation for 100 realizations of each 30-year period from the UKCP09 weather generator were employed in the DiCaSM model as daily input of the three time periods and the three emission levels. 


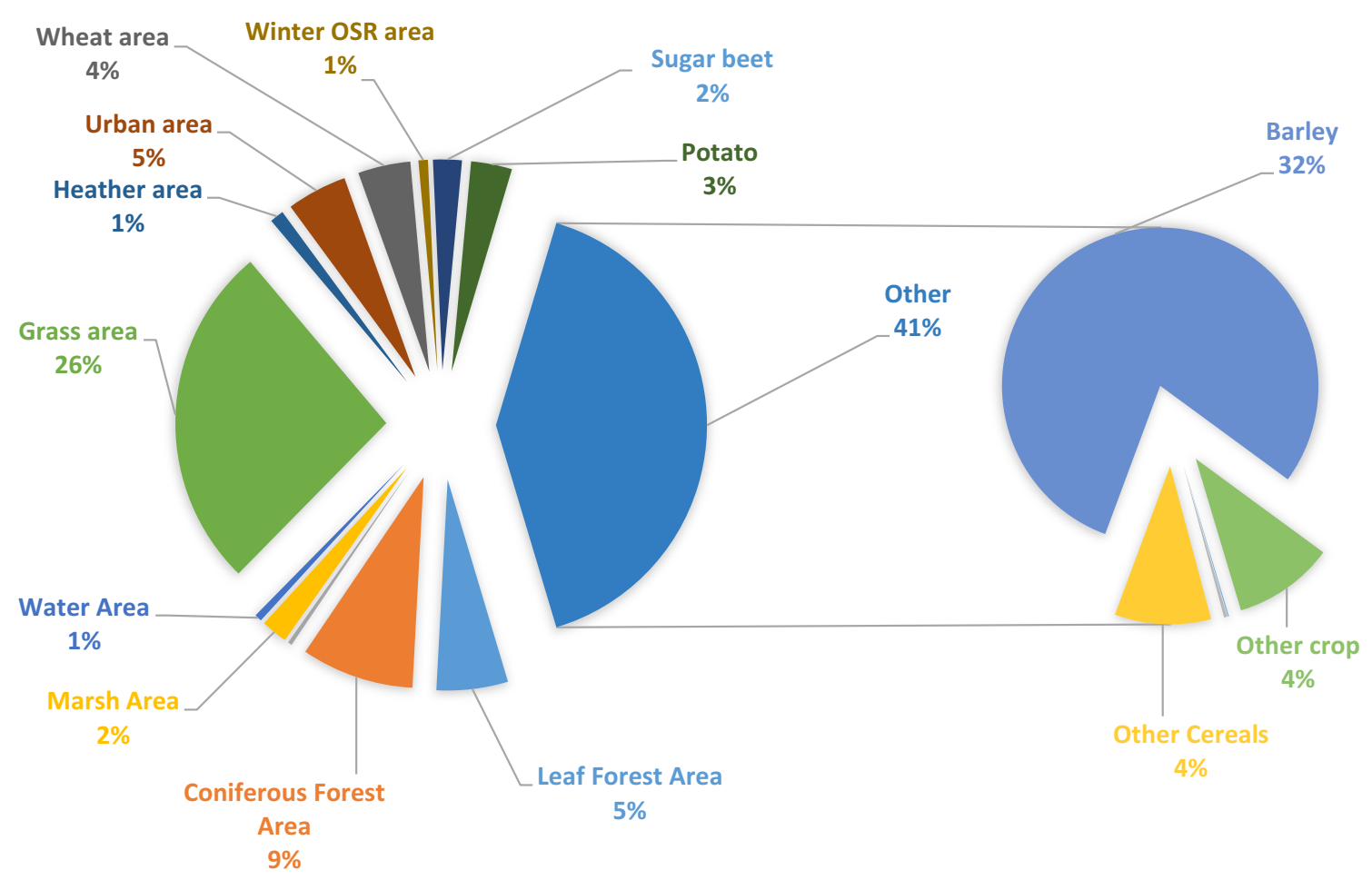

Fig. 6 Percentage of land use distribution for the Eden catchment

Table 1 Projected changes in temperature and precipitation, compared to 1961-1990 baseline, derived from joint probability data of UKCP09 climate change scenarios under low, medium and high emission scenarios for the 2020s, 2050s and 2080s (30-years' time slices)

\begin{tabular}{|c|c|c|c|c|c|c|c|c|c|c|c|c|c|}
\hline & & \multicolumn{4}{|c|}{ Low emissions } & \multicolumn{4}{|c|}{ Medium emissions } & \multicolumn{4}{|c|}{ High emissions } \\
\hline & & Winter & Spring & Summer & Autumn & Winter & Spring & Summer & Autumn & Winter & Spring & Summer & Autumn \\
\hline \multirow{3}{*}{$\begin{array}{l}\text { Change in } \\
\text { temperature } \\
\left({ }^{\circ} \mathbf{C}\right)\end{array}$} & $2020 \mathrm{~s}$ & 1.1 & 1.2 & 1.5 & 1.4 & 1.1 & 1.1 & 1.5 & 1.4 & 1 & 1.1 & 1.5 & 1.4 \\
\hline & $2050 \mathrm{~s}$ & 1.6 & 1.7 & 2 & 1.8 & 1.7 & 1.8 & 2.3 & 2.1 & 1.8 & 1.9 & 2.6 & 2.3 \\
\hline & $2080 \mathrm{~s}$ & 1.9 & 2 & 2.5 & 2.1 & 2.2 & 2.3 & 3.2 & 2.6 & 2.3 & 2.8 & 4 & 3.2 \\
\hline \multirow{3}{*}{$\begin{array}{l}\text { Change in } \\
\text { precipitation } \\
\text { (\%) }\end{array}$} & 2020 s & 4 & 2.5 & -4.6 & 6.9 & 5.1 & 2.5 & -5.5 & 5.1 & 3.7 & 2 & -7.9 & 2.5 \\
\hline & $2050 \mathrm{~s}$ & 6.7 & 1.5 & -8.9 & 4.8 & 11.1 & 3.2 & -13.4 & 4.7 & 10.6 & 2.8 & -13.5 & 6.3 \\
\hline & $2080 \mathrm{~s}$ & 12 & 3.7 & -12.4 & 4.1 & 12.7 & 4.3 & -16 & 7.6 & 22.2 & 5.4 & -20.2 & 7.2 \\
\hline
\end{tabular}

Increased greenhouse gas emissions

The daily climatic variables data generated using UKCP09 weather generator were bias corrected using observation data for the historic 1961-1990 period. The bias correction was conducted before undertaking the modelling work. This study applied bias correction method using the 'qmap' package in R statistical tool (Gudmundsson et al., 2012).

\section{Developing the drought indices}

The most commonly used drought index is the Standardized Precipitation Index (SPI), designed by McKee et al. (1993). In addition to this, the $S P E I$ drought index was also applied. The SPEI is calculated by subtracting the evapotranspiration from the gross rain. Both SPI and SPEI are based on 
the deviation from the long-term average. Negative values indicate below average "dry periods" and positive values indicate above average precipitation "wet period". Therefore, they could easily be used to calculate the severity of both dry and wet events. In addition, this study also applied the Reconnaissance Drought Index $(R D I)$, based on Tsakiris et al. (2007), which is based on the ratio of precipitation to potential evapotranspiration over a certain period. The RDI is a good indicator for describing the agricultural, hydrological and meteorological drought. The Reconnaissance Drought Index $(R D I)$ was calculated as:

$a_{0}^{(i)}=\frac{\sum_{j=1}^{12} P_{i j} \text { OR } N R_{i j}}{\sum_{j=1}^{12} P E T_{i j} O R A E T_{i j}}$

$R D I_{n}^{i}=\frac{a_{0}^{(i)}}{\overline{a_{0}}}-1$

$R D I_{s t^{\circ}(k)}^{i}=\frac{y_{k}^{(i)}-\overline{y k}}{\partial}$

where $P_{i j}, \mathrm{NR}_{i j}$ and $P E T_{\mathrm{ij}}, \mathrm{AE} T_{\mathrm{ij}}$ are the precipitation, netrain and potential evapotranspiration, actual evapotranspiration of the $j_{t h}$ month of the $i_{t h}$ hydrological year, (hydrological year start from October), $\mathrm{a}_{0}$ is the arithmetic mean of the $a_{0}$ calculated for the number of years. In Eq. $6 y k$ is the arithmetic mean and $\hat{\sigma}$ is the standard deviation. The Reconnaissance Drought Index $(R D I)$ uses the ratio of rainfall to evapotranspiration to represent the hydrological system input and output balance. Should the output (losses) exceed the input, drier conditions and eventually drought would occur. The $R D I$ is commonly calculated using potential evapotranspiration and gross rainfall. In this study, we attempted to use the actual evapotranspiration and net rainfall as a second option. As with the $S P I$, the $R D I$ index also picked up all the drought events which were observed by the SPI index. However, the advantage of applying $R D I$ drought index is that it does not rely only on one factor, i.e. precipitation as it calculates the index using the rainfall relationship to the evapotranspiration and therefore incorporates the important influence of temperature. The Reconnaissance Drought Index has been used in a number of studies (Vangelis et al., 2013; Zarch et al., 2015; Afzal and Ragab 2019).

The RDI is comparable to the FAO Aridity Index (Tsakiris et al., 2007). The conventional RDI was adjusted so that total precipitation was replaced by net precipitation after deducting the interception by land cover from total precipitation and potential evaporation was replaced by actual evapotranspiration. The adjusted $R D I$ could represent agricultural drought more accurately. Further to SPI, SPEI, RDI and adjusted RDI, two other drought indices were considered: the soil moisture deficit (SMD) and wetness index (WI) of the root-zone. Using a range of drought indices helps in identifying different types of droughts. The SPI index could easily identify drought periods and as such is good at indicating 'meteorological drought', which is significantly based on rainfall deficiency. Hydrological drought is commonly associated with shortfall in runoff or groundwater recharge, here WI is the relevant index and for the agricultural drought, where availability of the soil water is a key for the crop growing season, SMD and RDI are the relevant indicators as they identify drought periods and the need for irrigation. SMD and the wetness index, WI of the root-zone are relevant for the drought risk assessment in agriculture. The Soil Moisture Deficit, SMD represents the deviation of soil moisture from the soil moisture at field capacity. Here zero means, the catchment's soil moisture is at field capacity level. The deviation gets larger when the soil moisture starts to fall below the field capacity, especially during summer and drought periods.

\section{Model uncertainty analysis}

The accuracy of the model results could be quantified with uncertainty analysis. One method for assessing the uncertainty level is the Generalized Likelihood Uncertainty Estimation (GLUE) which was proposed by Beven and Binley (1992) and Beven (2006). In this study, a detailed uncertainty analysis was conducted and is in the process of separate publication. Therefore, the uncertainty analysis will only be briefly highlighted hereunder. The uncertainty level was evaluated using a number of indicators such the Containing Ratio, $C R$ parameter (Xiong et al. 2009). CR is the percentage of observed stream flows which are enveloped by the prediction bounds (of 5 and 95\% likelihood-weighted quantiles). A high $C R$ for the estimated prediction bounds represents a good model fit.

\section{Results}

\section{Model calibration and validation of the streamflow}

Figure 7 shows the model performance and the comparison between the simulated and observed flow for the calibrated stream flow of year 2001-2005 and validation against stream flow for the year 1975-76. Overall the model performed extremely well for both the calibration and validation years. The percentage difference in the simulated and the observed flow was minimum. The figure shows the flow of the River Eden during the well-known dry period of the mid-1970s and shows that, even under these extremely dry conditions, the model performed very well when river flow was compared with the measured flow (Fig. 7).

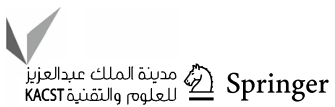


Fig. 7 DiCaSM model calibration for the year 2001-2005 (top) and validation for the year of 1975-1976 drought period (bottom)
Table 2 Model calibration and validation over the 42 years period between 1971-2012
Eden model calibration (2001-2005)

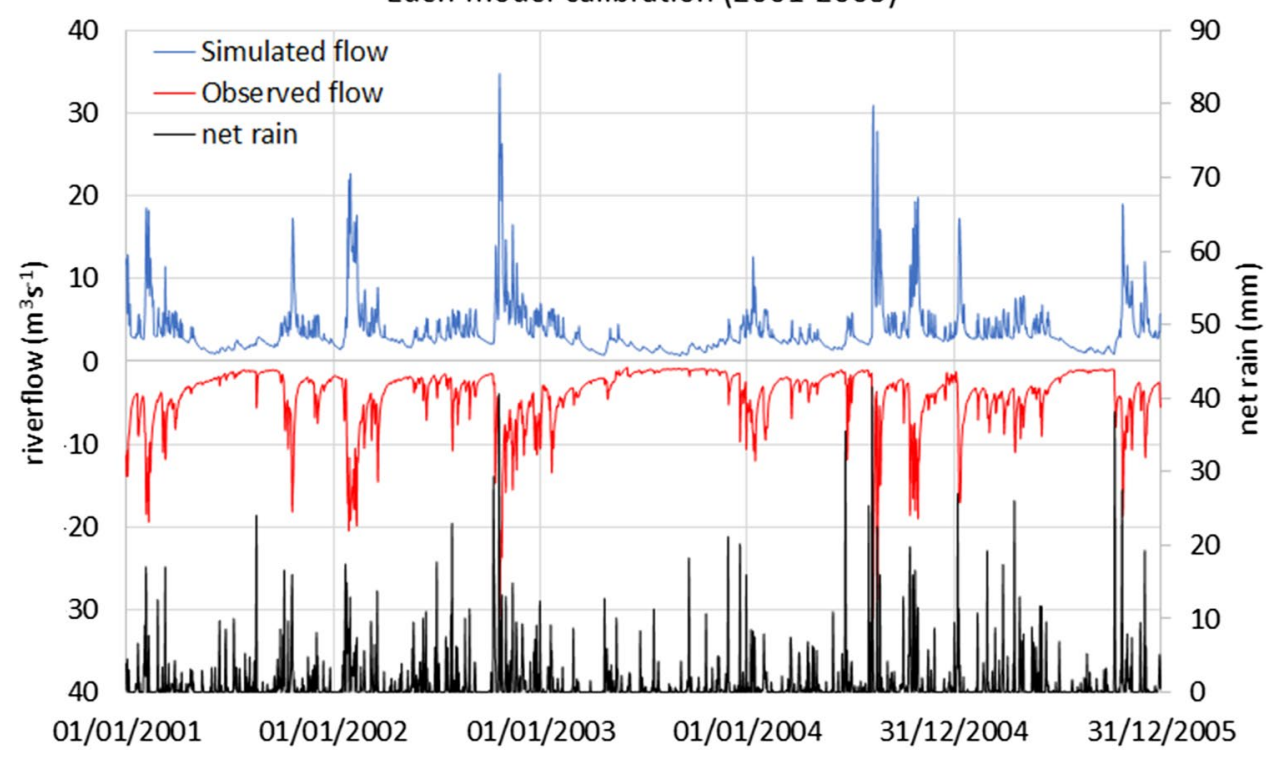

Eden model validation (1975-1976)

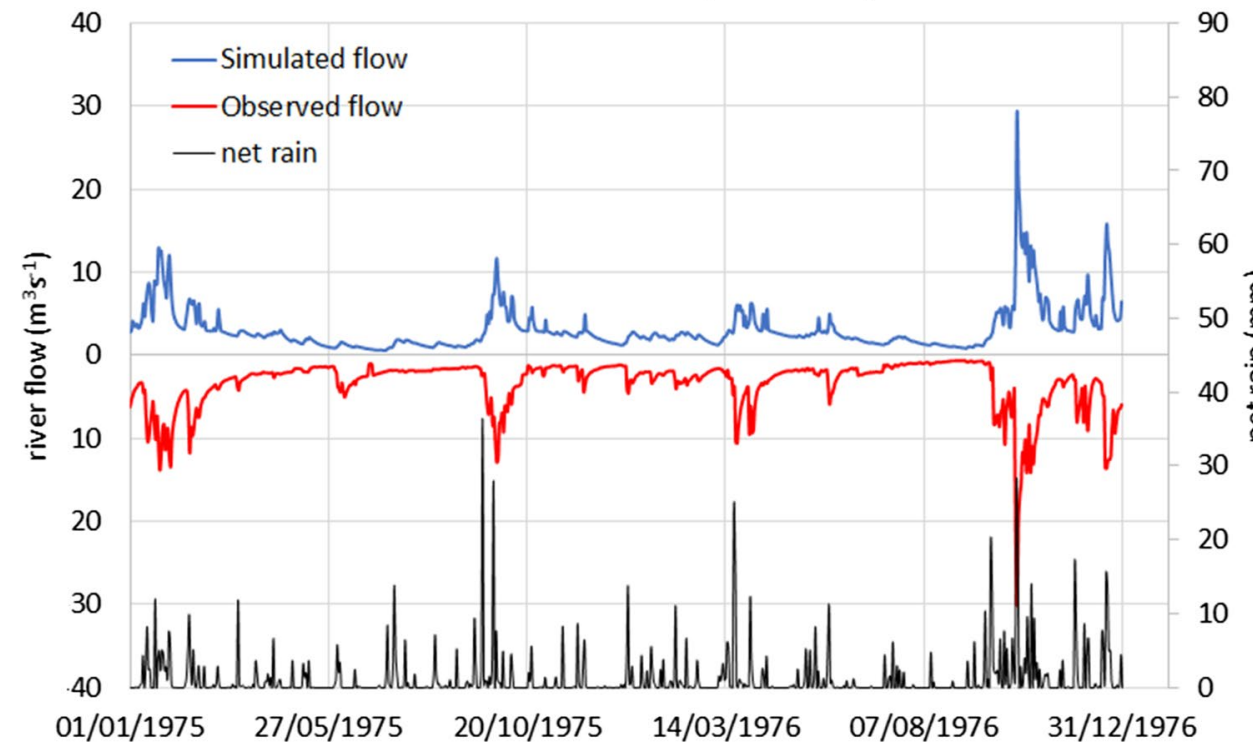

\begin{tabular}{llllllr}
\hline Time period & Simulation process & $\mathrm{R}^{2}$ & NSE & $\begin{array}{l}\text { Observed. daily } \\
\text { flow average } \mathrm{m}^{3} \mathrm{~s}^{-1}\end{array}$ & $\begin{array}{l}\text { Modelled daily } \\
\text { flow average } \mathrm{m}^{3} \mathrm{~s}^{-1}\end{array}$ & \% error \\
\hline $2001-2005$ & Calibration & 0.84 & 85.15 & 4.11 & 4.16 & -1.31 \\
$1971-1980$ & Validation & 0.81 & 79.97 & 3.60 & 3.54 & 1.69 \\
$1981-1990$ & Validation & 0.81 & 81.20 & 4.41 & 4.23 & 4.25 \\
$1991-2000$ & Validation & 0.78 & 78.20 & 4.11 & 4.25 & -3.29 \\
$2001-2012$ & Validation & 0.81 & 80.30 & 4.32 & 4.50 & 4.05 \\
$1971-2012$ & Validation & 0.80 & 79.96 & 4.11 & 4.13 & -0.48 \\
\hline
\end{tabular}

*NSE (Nash Sutcliffe Efficiency) coefficient was calculated from daily data 
Fig. 8 Relationship between observed and simulated daily flow for the Eden River in Scotland, UK
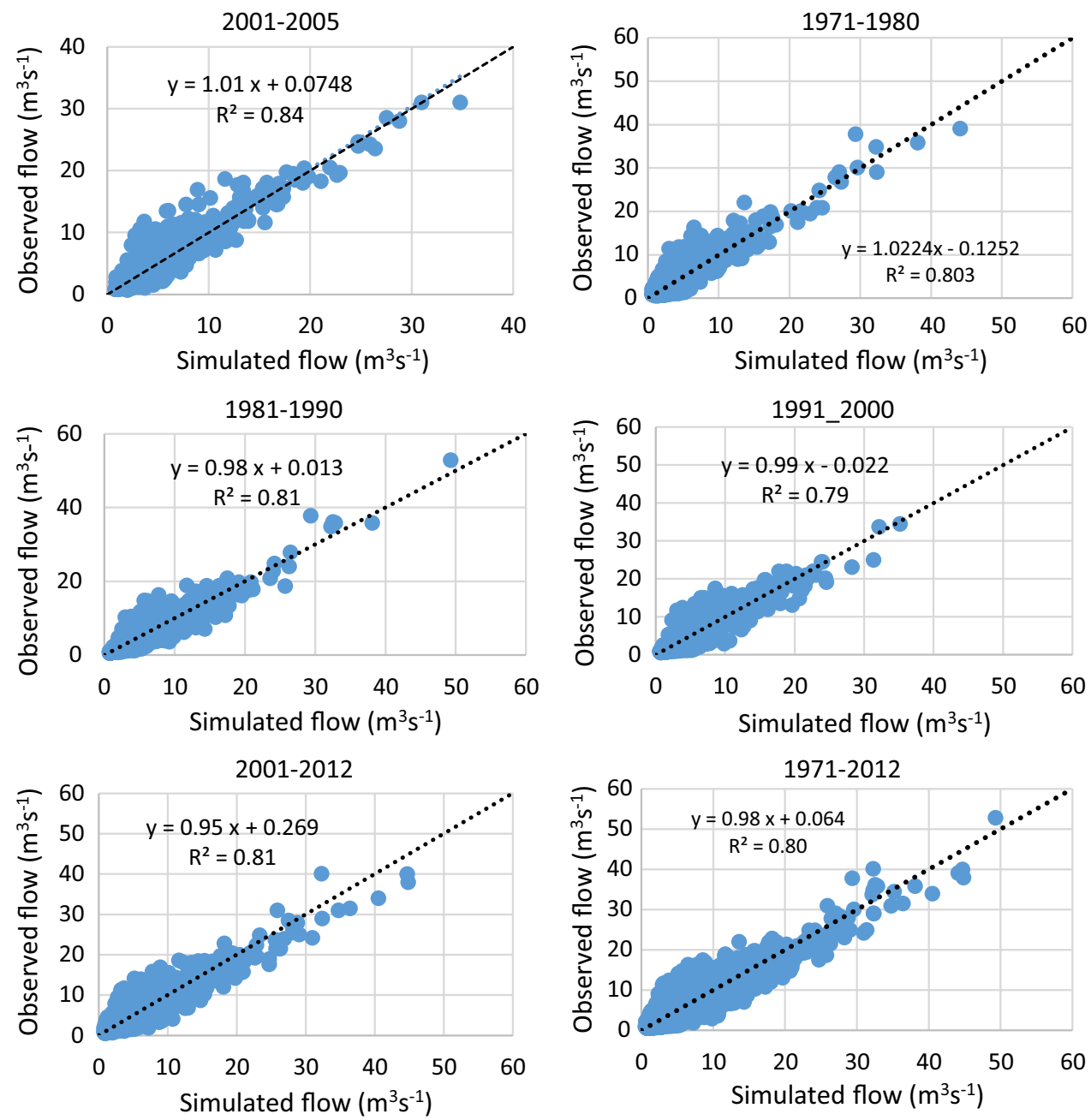

The model performance expressed as Nash-Sutcliffe Efficiency was $80 \%$ for the extremely dry year 1975-1976. For the following year 1976-1977, which was a reasonably wet year, the model gave a Nash-Sutcliffe Efficiency value of $87 \%$. Both simulated and observed flows clearly indicate that during the 1975-1976 drought event a significant amount of rainfall did not contribute much to the streamflow due to higher soil moisture deficit during the extreme drought event. Table 2 shows the results of the overall model performance using all model efficiency indicators. In general, model performance was very good when the simulated flow was compared to the observed flow. In this study, the model efficiency was expressed as percentage. The correlation between the observed and simulated flow is shown in Fig. 8 during the model calibration and validation stages.

In addition to this, other model efficiency performance indicators such as $\mathrm{R}^{2}$ and the percentage error suggest that the model performed extremely well even during the dry periods of the 1970s when the streamflow was extremely low during the dry summer months. Table 2 shows the results of model efficiency during model calibration and validation stages; overall model performance was good when simulated streamflow was compared against the observed flow. However, sometimes the model slightly overestimated the flow during some dry summer months. This was possibly due to the river water abstraction by different users (e.g. farmers for irrigation). In addition, sometimes the model slightly underestimated the flow. This could be associated with the fact there is a treated wastewater plant that discharges its water back into the river at those times.

\section{Drought period identification}

The SPI and SPEI drought indicators were able to detect the main drought events that took place between 1961 and 2012 in the Eden catchment (Fig. 9). The SPI index clearly shows the drought episode of the 1970s, when it was significantly drier than normal from 1972 to 1976 . In comparison to the SPI, the SPEI drought index showed slightly higher severity of the both dry and wet events as this index also considers water losses due to the evapotranspiration. Assessments of precipitation variations and the water losses due to 


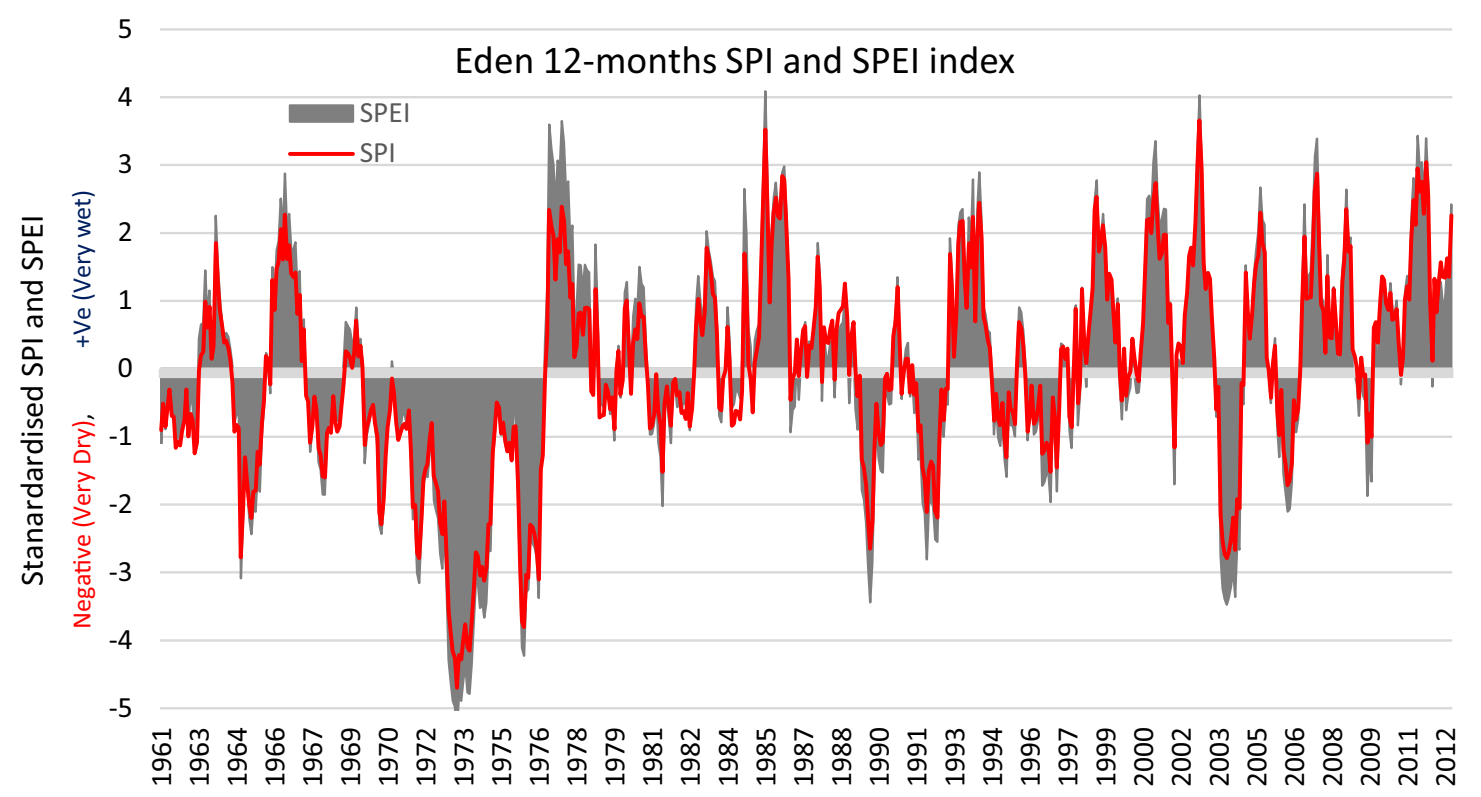

Fig. 9 The standardized precipitation Index (SPI) and standardized precipitation - evapotranspiration (SPEI) index from 1961 to 2012

Fig. 10 Reconnaissance drought index (RDI) and Adjusted RDI for the 1962 to 2012 time period

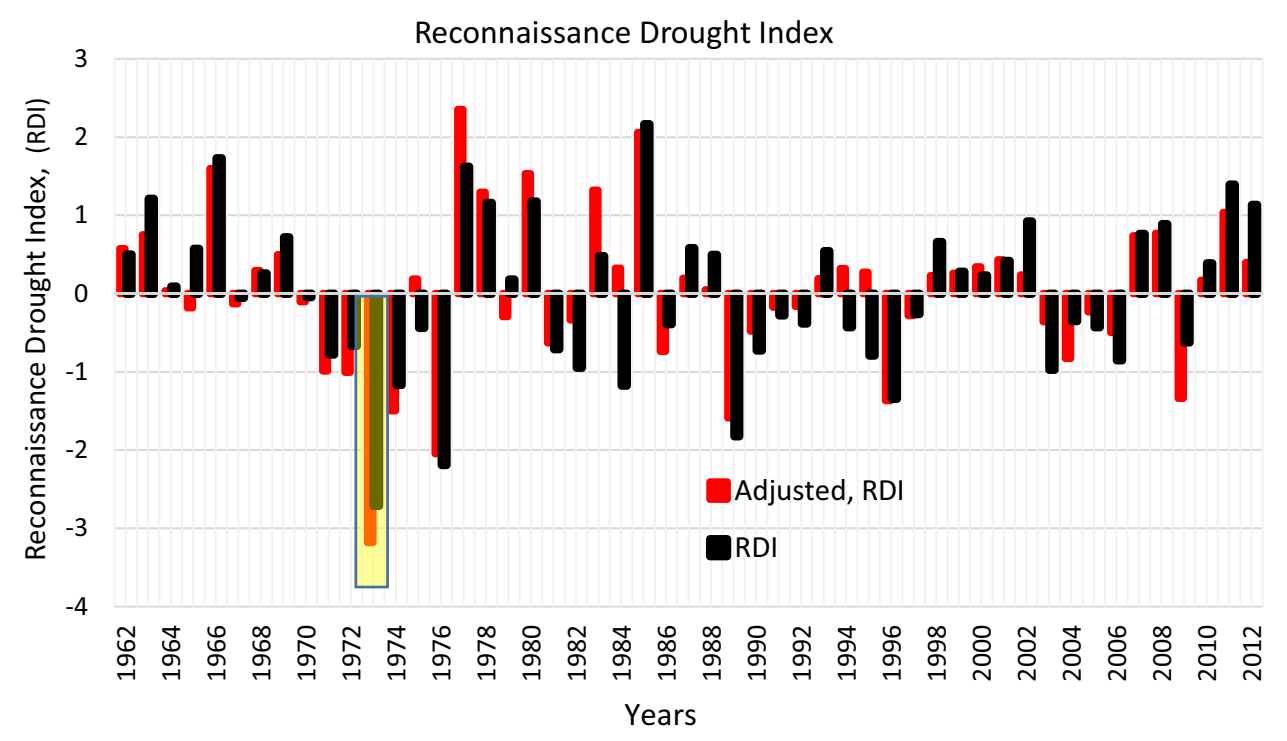

evapotranspiration are important as both significantly affect the streamflow and groundwater recharge. Therefore, SPI or SPEI index could be used as a good indicator for the meteorological drought, in addition to detecting hydrological droughts.

Over the 52 years both indices elucidated the successive dry events, as those occurred in the 1970s. The SPI/SPEI indices also help in identifying smaller magnitude drought events or drier periods which took place in the late 1980s, early 1990s and then in 2003-2004 and in 2009. The SPI index scale values mean: above 2.0 extremely wet, $1.5-1.99$ very wet, $1.0-1.49$ moderately wet, -0.99 to 0.99 near normal, -1.0 to -1.49 moderately dry, -1.5 to -1.99 severely dry and -2.0 and less, extremely dry (McKee et al., 1993). Figure 10 shows the comparison between the Reconnaissance Drought Index (RDI) and the adjusted RDI, showed slightly different severity levels than the $R D I$ especially during the extreme drought events. One should note that the adjusted $R D I$ index is based on realistic input of net rainfall (excluding interception losses by vegetation) and actual evapotranspiration, which reflect the actual losses from the soil and plants. Also, there is a strong correlation between the RDI and the SPI. Figure 9 shows that extreme drought conditions were observed in the years 1972-1976, 
when SPI reached a low value of -2 . Drier than average spells (RDI less than -1) were also observed in 1973, 1974, 1976, 1989, 1996, 2003 and 2009. It was also noticed that based on the SPI and SPEI the total percentage of the wet years was higher than the total percentage of dry years.

The other drought indices Soil Wetness Index, WI and soil moisture deficit, $S M D$ are shown in Fig. 10. The indicators clearly show the extreme drought in 1975 and 1976 and the recovery in 1977. The Wetness Index goes below the winter value of 1.0-0.3 during the extreme drought of the summer of 1975 and 1976 while the SMD mirrored the trend of WI.

\section{Model uncertainty analysis}

The observed stream flow time series were compared against simulated time series of 5 and $95 \%$ likelihood-weighted quantiles, and the number of observations contained within the 5 and 95\% GLUE uncertainty bounds was more than $70 \%$, showing that those set of parameters used can be considered acceptable, in order to be used for future projections, or further analysis. More details are being published separately.

\section{Impacts of climate change on the hydrology of the Eden catchment}

Considering low, medium and high greenhouse gas emissions trajectory up to 2099, the UKCP09 climate projections indicate a strong likelihood of lower summer rainfall and higher summer temperatures that will be felt more in the dry east than in the wet west of Scotland. The historic precipitation record across Scotland indicated that the average rainfall in the eastern part of Scotland is $802 \mathrm{~mm} /$ year, whereas in the western part is $1494 \mathrm{~mm} /$ year as reported by Afzal et al. (2015a).

\section{Future streamflow and groundwater recharge}

The streamflow projections under both the simplified change factors and the weather generator data suggest that the streamflow is more likely to be reduced by up-to $27.6 \%$ during the summer months, especially by the end of the century (Table 3). Under all emission scenarios, the summer streamflow is likely to decrease, by $9.6-17.8 \%$ in the 2020 s, by $14.9-21.34 \%$ in the 2050 s and by up-to $25.2 \%$ in the 2080s under high greenhouse gas emission scenarios. This could lead to very low streamflow which can cause drying up of the river, possibly leading to high risk of interruptions in domestic, industrial and agricultural water supply. The latter is more significant for the studied catchment as river water abstraction is very significant during the summer months. The study revealed that the groundwater recharge (Table 4) will also be reduced in the future. The largest decrease in groundwater recharge is likely to happen in the second half of the century, it may decrease by up-to $20.26 \%$ under the high emission scenario in the 2080's during the summer months. Overall, groundwater recharge during the summer months is much less than other seasons. The analysis of groundwater recharge suggests that climate change could have a significant impact on groundwater recharge, even though the climate models project an increase in winter precipitation for the three studied time periods and three emission scenarios (Table 1).
Table 3 Percentage changes in streamflow using the UKCP09 joint probability (J.P) change factor central estimates (highest probability level) and the UKCP09 weather generator (W.G) for different climate change scenarios

\begin{tabular}{|c|c|c|c|c|c|c|}
\hline \multirow{2}{*}{$\begin{array}{l}\text { Periods } \\
\text { Season }\end{array}$} & \multicolumn{2}{|l|}{ Low 2020s } & \multicolumn{2}{|l|}{ Low 2050s } & \multicolumn{2}{|l|}{ Low 2080s } \\
\hline & J. P & W. G & J. P & W. G & J. P & W. G \\
\hline Winter & 15.70 & 9.10 & 18.00 & 6.20 & 23.20 & 9.10 \\
\hline Spring & 13.90 & 13.90 & 13.10 & 19.20 & 16.70 & 13.90 \\
\hline Summer & -9.60 & -16.90 & -14.90 & -18.50 & -19.90 & -16.90 \\
\hline \multirow[t]{3}{*}{ Autumn } & -2.00 & -6.60 & -5.90 & -12.10 & -8.20 & -6.60 \\
\hline & Medium 2020s & & Medium 2050s & & Medium 2080s & \\
\hline & J. P & W. G & J. P & W. G & J. P & W. G \\
\hline Winter & 16.38 & 5.49 & 22.80 & 18.15 & 24.66 & 20.83 \\
\hline Spring & 14.40 & 14.52 & 15.41 & 20.98 & 16.57 & 34.52 \\
\hline Summer & -10.52 & -16.07 & -18.91 & -21.34 & -21.37 & -17.35 \\
\hline \multirow[t]{3}{*}{ Autumn } & -4.40 & -9.28 & -7.06 & -8.78 & -5.56 & -3.72 \\
\hline & High 2020s & & High 2050s & & High 2080s & \\
\hline & J. P & W. G & J. P & W. G & J. P & W. G \\
\hline Winter & 14.40 & 5.50 & 22.30 & 17.60 & 36.10 & 33.10 \\
\hline Spring & 13.60 & 7.30 & 14.90 & 18.60 & 19.40 & 33.50 \\
\hline Summer & -13.40 & -17.80 & -19.10 & -18.30 & -25.20 & -19.00 \\
\hline Autumn & -7.80 & -10.00 & -5.90 & -4.40 & -7.60 & -7.80 \\
\hline
\end{tabular}


Table 4 Percentage changes in groundwater recharge using the UKCP09 joint probability change factor central estimates (highest probability level) and the UKCP09 weather generator for different climate change

\begin{tabular}{|c|c|c|c|c|c|c|}
\hline \multirow{2}{*}{$\begin{array}{l}\text { Periods } \\
\text { Season }\end{array}$} & \multicolumn{2}{|l|}{ Low $2020 \mathrm{~s}$} & \multicolumn{2}{|l|}{ Low 2050s } & \multicolumn{2}{|l|}{ Low 2080s } \\
\hline & J. P & W. G & J. P & W. G & J.P & W. G \\
\hline Winter & 0.55 & 0.72 & 1.61 & 2.47 & 5.02 & 5.62 \\
\hline Spring & -3.73 & -5.65 & -5.56 & -5.18 & -2.21 & -4.02 \\
\hline Summer & -0.09 & -0.62 & -2.19 & -3.29 & -9.74 & -11.21 \\
\hline \multirow[t]{3}{*}{ Autumn } & 2.80 & -1.28 & 0.22 & -3.13 & 3.95 & -3.65 \\
\hline & Medium 2020s & & Medium 2050s & & Medium 2080s & \\
\hline & J. P & W. G & J. P & W. G & J. P & W. G \\
\hline Winter & 1.09 & 1.13 & 3.94 & 4.72 & 4.28 & 5.37 \\
\hline Spring & -3.12 & -1.49 & -4.68 & -2.67 & -4.54 & -2.86 \\
\hline Summer & -3.41 & -2.63 & -13.32 & -14.09 & -12.18 & -17.10 \\
\hline \multirow[t]{3}{*}{ Autumn } & 1.47 & -2.02 & -0.48 & -0.85 & -0.31 & -2.26 \\
\hline & High 2020s & & High 2050s & & High 2080s & \\
\hline & J. P & W. G & J. P & W. G & J. P & W. G \\
\hline Winter & 0.15 & 0.82 & 3.36 & 6.89 & 9.94 & 9.47 \\
\hline Spring & -3.58 & -6.00 & -5.15 & -3.29 & -4.26 & -4.06 \\
\hline Summer & -2.15 & -2.89 & -7.96 & -11.86 & -17.89 & -20.26 \\
\hline Autumn & -0.60 & -1.85 & -0.17 & -2.21 & -2.41 & -1.91 \\
\hline
\end{tabular}

The groundwater recharge varies according to the season, for example, the recharge during summer months with low rainfall and higher temperature could decrease by up-to $20.26 \%$ under high emission scenarios of the 2080's, whereas the increase in winter precipitation would be counterbalanced by the higher water losses due to the increased evapotranspiration. The latter leads to an increase in soil moisture deficit and subsequently low recharge particularly during dry periods. Drier summers could also lead to increased soil moisture deficit extending into the autumn and could shorten the winter recharge season (Herrera-Pantoja and Hiscock, 2008). The decrease in recharge in summer could be balanced by the increased winter precipitation as projected under all emission scenarios. However, it is likely that in the future, the increase in winter precipitation would come as extreme precipitation events over a short period of time (Alexander et al., 2005). This would lead to surface run off rather than increasing the groundwater recharge. A slight increase in groundwater recharge is projected during the winter and spring seasons by the end of this century, however, the increase would be small (Table 4).

\section{Future drought risk}

Under the climate change scenarios, both the simplified joint probability change factors and weather generator climate variables showed an increase in soil moisture deficit and actual evapotranspiration under all emission scenarios. However, in this section results are shown for the weather generator. The analysis reveals that the highest increase in
Table 5 Drought indicators: soil moisture deficit and actual evapotranspiration for the Eden catchment projected under different climate change scenarios using UKCP09 weather generator data

\begin{tabular}{|c|c|c|c|c|c|c|c|}
\hline \multirow[t]{2}{*}{ Scenarios } & \multirow{2}{*}{$\begin{array}{l}\text { Season } \\
\text { Season }\end{array}$} & \multicolumn{3}{|c|}{ Soil moisture deficit } & \multicolumn{3}{|c|}{ Actual evapotranspiration } \\
\hline & & Low & Medium & High & Low & Medium & High \\
\hline \multirow[t]{4}{*}{$2020 s$} & Winter & 22.01 & 21.22 & 28.01 & 54.19 & 53.78 & 54.07 \\
\hline & Spring & 27.22 & 23.19 & 25.94 & 31.02 & 26.7 & 26.66 \\
\hline & Summer & 26.87 & 25.37 & 29.4 & 13.12 & 11.51 & 12.93 \\
\hline & Autumn & 32.07 & 30.11 & 38.29 & 49.99 & 50.55 & 50.24 \\
\hline \multirow[t]{4}{*}{$2050 \mathrm{~s}$} & Winter & 37.89 & 42.35 & 49.52 & 89.56 & 108.52 & 129.8 \\
\hline & Spring & 41.29 & 44.58 & 48.31 & 40.3 & 44.56 & 45.47 \\
\hline & Summer & 41.76 & 50.88 & 54.45 & 16.59 & 16.76 & 19.87 \\
\hline & Autumn & 51.3 & 61.13 & 68.36 & 58.01 & 66.21 & 74.67 \\
\hline \multirow[t]{4}{*}{$2080 s$} & Winter & 90.49 & 58.84 & 67.27 & 105.97 & 151.13 & 149.72 \\
\hline & Spring & 65.06 & 53.59 & 75.79 & 40.95 & 50.04 & 58.92 \\
\hline & Summer & 43.4 & 68.08 & 82.33 & 20.75 & 25.83 & 29.44 \\
\hline & Autumn & 58.46 & 85.77 & 110.86 & 66.28 & 82.55 & 110.02 \\
\hline
\end{tabular}


soil moisture deficit and evapotranspiration was observed under high emission scenarios, and the smallest changes were projected under low emission scenarios (Table 5). Similar results were also found when the analysis was carried with the joint probability results. These findings are consistent with other studies including Thompson (2012) who reported an increase in annual evapotranspiration in the Southwest of Scotland. The biggest change in actual evapotranspiration and soil moisture deficit was observed under high emission scenarios, which significantly affect both the surface and groundwater resource availability. This is likely to be the result of an increase in temperature associated with lower precipitation.

To study the impact of projected changes in rainfall and water losses due to the evapotranspiration, the future Reconnaissance Drought Index $(R D I)$ was calculated using the net-rain and actual evapotranspiration for all three emission scenarios for all three selected time periods 2020s, 2050s and 2080s using the three 30-years data sets. The analyses of the 90 years reveal that the highest number of six extremely dry events were observed under the high emission scenarios (RDI value was -2 or less), whereas under medium and low emission scenarios four and two extreme events were observed, respectively. In comparison to the high and low emission scenarios, the severe drought event (RDI was between -1.5 to -1.99 ) was observed six times under medium and three times under both low and high emission scenarios (Fig. 11). The highest number of four severe drought events occurred in the 2050s under medium emission scenarios. In contrary to the high and medium emission scenarios, the highest number of moderate droughts was observed under low emission scenarios. Over the 90-years studied period under low emission scenarios, twelve moderate drought events occurred whereas

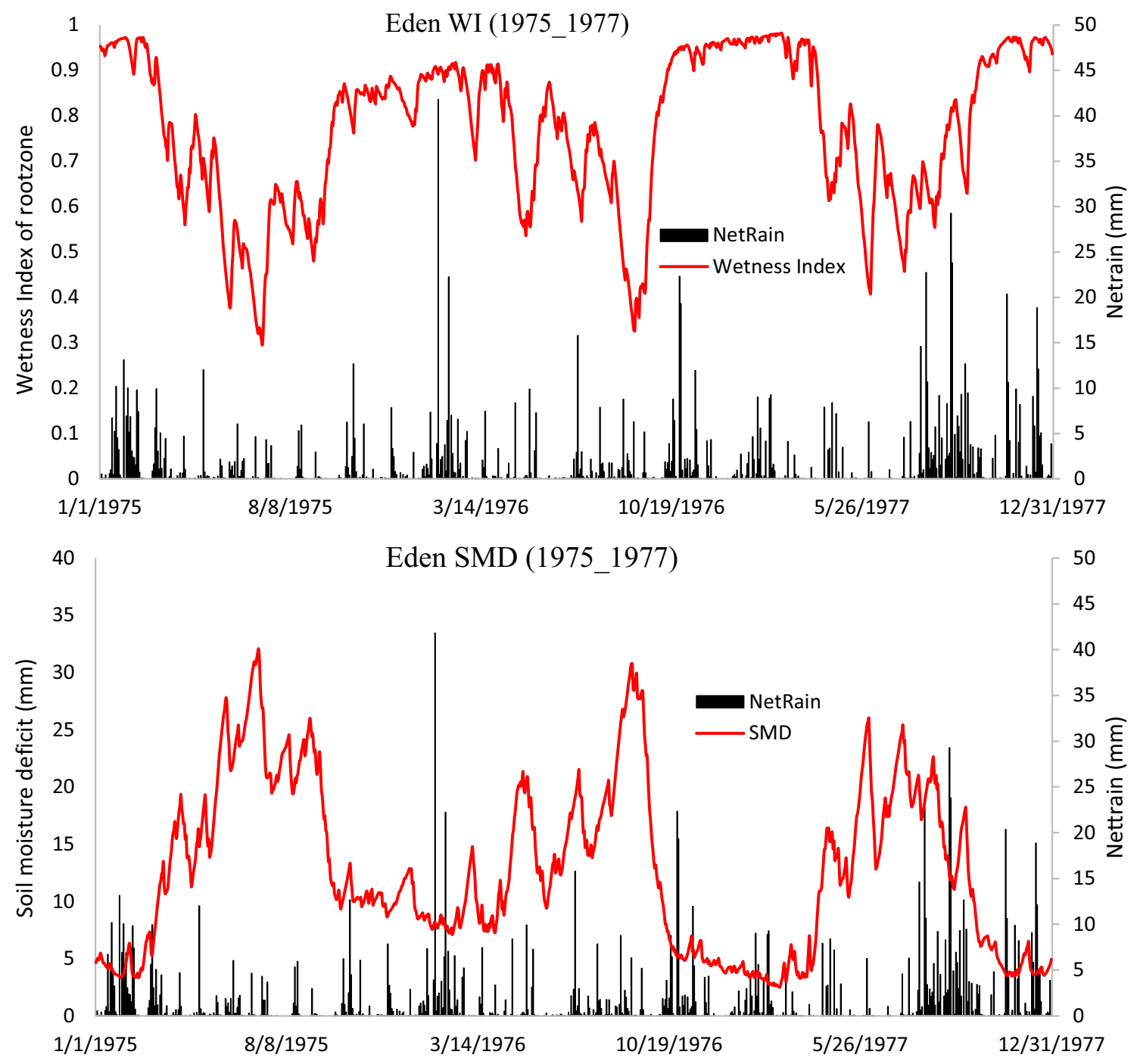

Fig. 11 Eden wetness index (Top) and soil moisture deficit (Bottom) for the years 1975-1977 
under medium and high emission scenarios three moderate drought events each were found. Overall more extreme and severe drought events were observed under high and medium emission scenarios as compared to the low emission scenarios and at least one extreme drought episode was observed in each 30-years studied period (the 2020s, 2050s, and 2080s). Whereas for the historic study period, during the 1961-2012, two extreme drought events occurred during the 1970s and another four moderate drought events took place during the 1961-2012 period. Not only has the occurrence of the drought events but also the frequency and the duration have a significant effect on the water supply. The occurrence of extreme drought events could significantly affect the agriculture as more irrigation would be required to irrigate the crops during the dry seasons in the future. This is reported in a study by Brown et al. (2012) who predicted a very significant increase in irrigation water demand greater than 500 million liters in the Eden catchment area.

\section{Discussion}

This study analyzed the impact of future climate change scenarios on water resources availability and assessed the occurrence of past and potential future drought events in the Eden catchment. All the applied drought indices identified the extreme drought events of the 1970s, however, the reconnaissance drought index calculated from actual evapotranspiration and net rainfall showed slightly better results than the other indices. The results of the standardized precipitation index, SPI clearly indicated significantly negative deviation from average precipitation in the 1970s, which is well supported by other drought indices like Reconnaissance Drought Index (RDI), soil moisture deficit
$(S M D)$ and the wetness index $(W I)$ for the drought period of 1975-1976. These indices could be used as good indicators to detect the severity of the drought and its implications (Afzal and Ragab 2019). For example, in agriculture, when soil moisture deficit, SMD or Wetness Index, reach a critical level, crops will require irrigation. The WI value, if close to 1 , would indicate a saturated catchment with a possible runoff generation during the next rainfall event. It is a help to reservoir managers to know the WI in real time so that they can manage their reservoirs efficiently. The $R D I$ would be helpful for short and long-term planning by water authorities and water companies.

In general, in the context of drought, although Scotland has not experienced many drought events in the past, there is a huge regional difference in terms of water resources availability/water supply and demand. In some regions of Scotland, water supplies remain at risk due to the decreased flow, more particularly during the summer when water demand is high. The modelling results provided evidence of low river flows due to water abstraction during the summer months. The findings of the study proved that the DiCaSM model is a good tool to predict river flow and can simulate the effects of climate change on the different elements of the hydrological cycle. The climate change scenarios suggested a decrease in groundwater recharge in the Eden catchment. The decrease in groundwater recharge was significant during the summer season but overall groundwater recharge decreased by less than $10 \%$ under all emission scenarios. This is consistent with other studies, including Herrera-Pantoja and Hiscock (2008) who predicted a decrease of $6 \%$ groundwater recharge in Paisley, West Scotland.

Findings of the present study suggest that the streamflow and groundwater recharge are likely to decrease significantly
Fig. 12 Comparison of different drought events for the historic (1961-2012) and for the future (2020s, 2010-2039), (2050s, 2040-2069), (2080s, 20702099) under low, medium and high emission scenarios

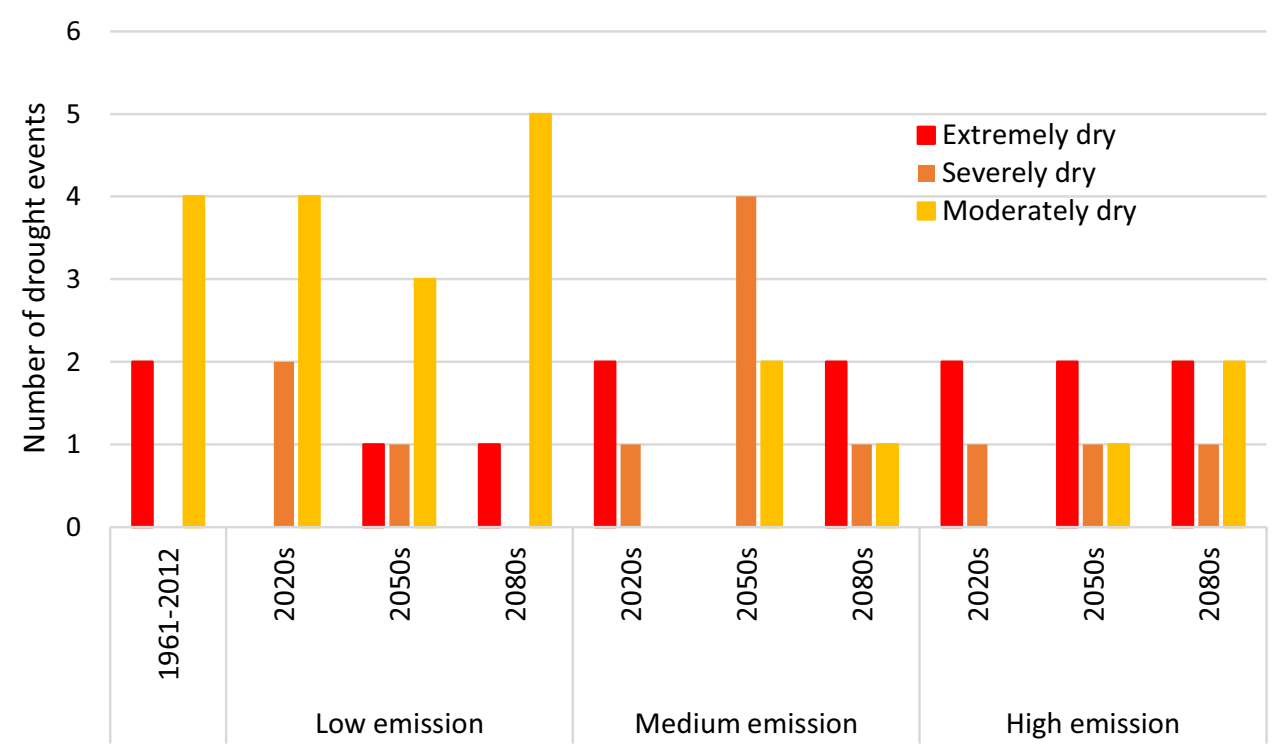


during the summer months under all emission scenarios which would have an impact on water availability/supply. This is evident from the drought index RDI, which shows more extreme droughts in the second half of the century (Fig. 12). Future changes in streamflow can significantly affect water supply in Scotland, more importantly, the reduced water supply in the summer could be problematic for irrigation. Considering the possible future increase in water demand for agriculture, one possible solution would be to transfer water from the rivers and lakes of water-rich parts of Scotland in the west to the drought-prone parts in the east. The Eden catchment might occasionally be under risk when the water demand exceeds the water supply, especially during summertime. The implication of water abstractions during drought and low flow period would reduce river flows possibly below the minimum environmental limit. Alternatively, restrictions on abstraction to maintain the minimum environmental flows may restrict crop yields, food and bioenergy production.

\section{Conclusions}

The following is a summary of the key findings.

- The historical analysis of fifty-two years of data revealed a good agreement between the simulated and the observed streamflow and all the three drought indices, RDI, SMD, and WI were able to identify past drought periods and their severities, especially the well observed drought of the 1970s.

- Over annual and seasonal time scales, the severity of the drought events significantly increased over time and the drought severity was greater in the second half of the current century, as shown by several the drought indices.

- All the applied drought indices (SMD, WI, and RDI) identified an increase in the severity of the drought under future climatic scenarios. Under high greenhouse emission scenarios, the drought severity was higher due to the increasing temperature and subsequent increase in water losses through evapotranspiration, thus reducing soil moisture availability, surface runoff to streams and recharge to groundwater.

- The standardized RDI based on gross rainfall and potential evapotranspiration showed slightly different severity levels, especially during the extreme drought events, than the adjusted RDI index based on realistic input of net rainfall (excluding interception losses by vegetation cover) and actual evapotranspiration which reflects the actual losses from soil and plants.

- These findings help in planning for perhaps extra water infrastructure work if needed, such as constructing more reservoirs (however, this option might not be acceptable by local communities due to possible environmental impact) or water transfer pipelines from water-rich to water-poor regions and planning for irrigation water demand under different climatic conditions.

- The findings of the study suggest increasing the storage capacity of the three main reservoirs adjacent to the catchment (Upper Glendevon, Lower Glendevon and Glensherup) which are generally considered as reservoirs at risk during droughts.

Acknowledgement The authors acknowledge the NERC funding for this 4-years "Drought Risk and You, DRY" project, grant reference NE/L010292/1. We are also very thankful to our CEH colleagues especially Yan Weigang, Egon Dumont, James Blake and Virginie Keller, who helped us in preparing the model input data and Nikolaos Vavlas, who helped with the preparation of UKCP09 climate change scenarios. The authors are also very thankful to Dr Owen Bramwell and Derek Ball from Scottish Water, Michael Wann from the Scottish Environmental Protection Agency and Dr. Andrew Black from the University of Dundee who arranged regular meetings and site visits and helped with accessing data sources. The authors would like to acknowledge the data sources: Background mapping from Ordnance Survey ('1:250 000 Scale Colour Raster'). Catchment boundary and gauging station location data from Centre for Ecology and Hydrology, see Morris and Flavin $(1990,1994)$ and the National River Flow Archive (NRFA, 2014). River and waterbody data from Centre for Ecology and Hydrology ('Digital Rivers 50km GB' Web Map Service). Land cover data from Centre for Ecology and Hydrology, Land Cover Map 2007 (25m raster, GB) Web Map Service, see Morton et al. (2007). Standardized Precipitation Index time series for IHU groups (1961-2012) [SPI_IHU_ groups] data licensed from NERC Centre for Ecology \& Hydrology. Soils data from the James Hutton Institute (1:250 000 Soils of Scotland Web Map Service, 'Qmsoils_UCSS_v1.1_WGS84 - 2013' layer). Hydrogeology data from British Geological Survey (DiGMapGB 1:625 000 scale digital hydrogeological data).

Funding The Natural Environment Research Council, NERC UK funding for 4-years "Drought Risk and You, DRY" project, Grant Reference NE/L010292/1.

\section{Compliance with ethical standards}

Conflicts of interest The authors declare that this work is original and not submitted anywhere for publication and have no conflict of interest with individuals or organizations.

Human and animal rights This work did not include human or animals and followed the work ethics laid by the Natural Environment Research Council of the UK.

Open Access This article is licensed under a Creative Commons Attribution 4.0 International License, which permits use, sharing, adaptation, distribution and reproduction in any medium or format, as long as you give appropriate credit to the original author(s) and the source, provide a link to the Creative Commons licence, and indicate if changes were made. The images or other third party material in this article are included in the article's Creative Commons licence, unless indicated otherwise in a credit line to the material. If material is not included in the article's Creative Commons licence and your intended use is not

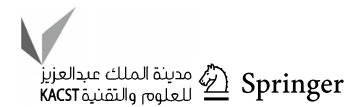


permitted by statutory regulation or exceeds the permitted use, you will need to obtain permission directly from the copyright holder. To view a copy of this licence, visit http://creativecommons.org/licenses/by/4.0/.

\section{References}

Adeloye AJ, Low JM (1996) Surface-water abstraction controls in Scotland. J Chart Inst Water Environ Manag 10:123-129

Afzal M, Ragab R (2019) Drought risk under climate and land use changes: implication to water resource availability at catchment scale. Water 11:1790. https://doi.org/10.3390/w11091790

Afzal M, Gagnon AS, Mansell MG (2015a) Changes in the variability and periodicity of precipitation in Scotland. Theoret Appl Climatol 119:135-159

Afzal M, Gagnon AS, Mansell MG (2015b) The impact of projected changes in climate variability on the reliability of surface water supply in Scotland. Water Sci Technol Water Supply 15:736-745

Alexander LV, Tett SF, Jonsson T (2005) Recent observed changes in severe storms over the United Kingdom and Iceland. Geophys Res Lett 32

Allen RG, Pereira LS, Raes D, Smith M (1998) Crop evapotranspiration-guidelines for computing crop water requirements-FAO Irrigation and drainage paper $56 \mathrm{FAO}$, Rome $300 \mathrm{D} 05109$

Barnett C, Hossell J, Perry M, Procter C, Hughes G (2006) Patterns of climate change across Scotland: Technical Report. SNIFFER Project CC03, Scotland \& Northern Ireland Forum for Environmental Research, Edinburgh

Beven K (2006) A manifesto for the equifinality thesis. J Hydrol 320:18-36

Beven K, Binley A (1992) The future of distributed models: model calibration and uncertainty prediction. Hydrol Process 6:279-298

Brown I, Dunn S, Matthews K, Poggio L, Sample J, Miller D (2012) Mapping of water supply-demand deficits with climate change in Scotland: land use implications. CREW report 2011/CRW006

D’Agostino DR, Trisorio LG, Lamaddalena N, Ragab R (2010) Assessing the results of scenarios of climate and land use changes on the hydrology of an Italian catchment: modelling study. Hydrol Process 24:2693-2704

DEFRA. Government Agricultural Census for England, Wales and Scotland [Online]. CEH archive: Defra. Available: https://catal ogue.ceh.ac.uk/documents/3f95cd4b-391f-4226-aa87-832b6 d25038b [Accessed 05/12/2014 2014]. 2015.

Fisher AC, Rubio SJ (1997) Adjusting to climate change: Implications of increased variability and asymmetric adjustment costs for investment in water reserves. Environ Econ Manag 34:207-227

Gosling R (2014) Assessing the impact of projected climate change on drought vulnerability in Scotland. Hydrol Res 45:806-816

Gudmundsson L, Bremnes J, Haugen J, Engen-Skaugen T (2012) Downscaling RCM precipitation to the station scale using statistical transformations-a comparison of methods. Hydrol Earth Syst Sci 16:3383

Herrera-Pantoja M, Hiscock K (2008) The effects of climate change on potential groundwater recharge in Great Britain. Hydrol Process $22: 73-86$

Hulme M (2002) Climate change scenarios for the United Kingdom: the UKCIP02 scientific report. Tyndall Centre for Climate Mental Sciences University

Kay A, Bell V, Blyth E, Crooks S, Davies H, Reynard N (2013) A hydrological perspective on evaporation: historical trends and future projections in Britain

Macdonald AM, Robins NS, Ball DF, Dochartaigh BEO (2005) An overview of groundwater in Scotland. Scott J Geol 41:3-11

Mayes J (2000) Changing regional climatic gradients in the United Kingdom. Geogr J 166:125-138
Mckee TB, Doesken NJ, Kleist J (1993) The relationship of drought frequency and duration to time scales. In: Proceedings of the 8th conference on applied climatology. American Meteorological Society, Boston, pp 179-183

Montenegro A, Ragab R (2010) Hydrological response of a Brazilian semi-arid catchment to different land use and climate change scenarios: a modelling study. Hydrol Process 24:2705-2723

Montenegro S, Ragab R (2012) Impact of possible climate and land use changes in the semi arid regions: a case study from North Eastern Brazil. J Hydrol 434:55-68

Morris D, Flavin R (1994) Sub-set of the UK $50 \mathrm{~m}$ by $50 \mathrm{~m}$ hydrological digital terrain model grids. NERC, Institute of Hydrology, Wallingford

Morris D, Flavin R, Moore R (1990) A digital terrain model for hydrology

Murphy JM, Booth BB, Collins M, Harris GR, Sexton DM, Webb MJ (2007) A methodology for probabilistic predictions of regional climate change from perturbed physics ensembles. Philos Trans R Soc A Math Phys Eng Sci 365:1993-2028

Murphy JM, Sexton D, Jenkins G, Booth B, Brown C, Clark R, Collins M, Harris G, Kendon E, Betts R (2009) UK climate projections science report: climate change projections

Nash JE, Sutcliffe JV (1970) River flow forecasting through conceptual models part I: a discussion of principles. J Hydrol 10:282-290

NRFA. National River Flow Archive [Online]. Available: https://nrfa. ceh.ac.uk/ [Accessed 03/11/2014 2014]. 2014.

Perry M, Devon E (2006) National climate information centre climate memorandum No 21. Met Office, science programme manager, Devon, EX1 3PB

Ragab R, Bromley J (2010) IHMS: integrated hydrological modelling system. Part 1. Hydrological processes and general structure. Hydrol Process 24:2663-2680

Ragab R, Bromley J, Dörflinger G, Katsikides S (2010) IHMS: integrated hydrological modelling system. part 2. Application of linked unsaturated, DiCaSM and saturated zone, MODFLOW models on Kouris and Akrotiri catchments in Cyprus. Hydrol Process 24:2681-2692

Robenson E, Blyth E, Clark D, Comyn-Platt E, Finch J, Rudd A (2015) Climate hydrology and ecology research support system potential evapotranspiration dataset for Great Britain (1961-2015) [CHESS-PE]

Singh CR, Thompson JR, French JR, Kingston DG, Mackay AW (2010) Modelling the impact of prescribed global warming on runoff from headwater catchments of the Irrawaddy River and their implications for the water level regime of Loktak Lake, northeast India. Hydrol Earth Syst Sci 14:1745-1765

Smith K (1977) Water resource management in Scotland. Scott Geogr Mag 93:66-79

Tanguy M, Dixon H, Prosdocimi I, Morris D, Keller V (2016) Gridded estimates of daily and monthly areal rainfall for the United Kingdom (1890-2015)[CEH-GEAR]. NERC Environmental Information Data Centre

Thompson J (2012) Modelling the impacts of climate change on upland catchments in southwest Scotland using MIKE SHE and the UKCP09 probabilistic projections. Hydrol Res 43:507-530

Tsakiris G, Pangalou D, Vangelis H (2007) Regional drought assessment based on the Reconnaissance Drought Index (RDI). Water Resour Manage 21:821-833

Vangelis H, Tigkas D, Tsakiris G (2013) The effect of PET method on Reconnaissance Drought Index (RDI) calculation. J Arid Environ $88: 130-140$

Wade SD, Rance J, Reynard N (2013) The UK climate change risk assessment: assessing the impacts on water resources to inform policy makers. Water Resour Manage 27:1085-1109 
Werritty A, Sugden D (2012) Climate change and Scotland: recent trends and impacts. Earth Environ Sci Trans R Soc Edinburgh 103:133-147

Xiong L, Wan M, Wei X, O'Connor KM (2009) Indices for assessing the prediction bounds of hydrological models and application by generalised likelihood uncertainty estimation/Indices pour évaluer les bornes de prévision de modèles hydrologiques et mise en œuvre pour une estimation d'incertitude par vraisemblance généralisée. Hydrol Sci J 54:852-871

Zarch MAA, Sivakumar B, Sharma A (2015) Droughts in a warming climate: a global assessment of Standardized precipitation index (SPI) and Reconnaissance drought index (RDI). J Hydrol 526:183-195

Publisher's Note Springer Nature remains neutral with regard to jurisdictional claims in published maps and institutional affiliations. 